\title{
Adjunct low level laser therapy (LLLT) in a morbidly obese patient with severe COVID-19 pneumonia: A case report
}

\author{
Scott A. Sigman $M D^{1}$, Soheila Mokmeli $\mathrm{MD}^{2}$, Mariana A. Vetrici MD, $\mathrm{PhD}^{3}$
}

\begin{abstract}
S. A. Sigman, S. Mokmeli, M. A. Vetrici. Adjunct low level laser therapy (LLLT) in a morbidly obese patient with severe COVID-19 pneumonia: A case report Can J Respir Ther 2020;56:52-56. doi: 10.29390/cjrt-2020-022.

Introduction: COVID-19 poses a higher risk of complications in obese patients due to low respiratory system compliance, increased inflammatory cytokines, and an activated immune system secondary to excess adiposity. Low level laser therapy (LLLT) has significant anti-inflammatory effects and reduces inflammatory cytokines. It is noninvasive and approved for pain management and musculoskeletal injuries. Data from human and experimental animal models of respiratory tract disease suggests that LLLT reduces inflammation and promotes lung healing.

Case and outcomes: A morbidly obese 32-year-old Asian female with severe COVID-19 received four consecutive once-daily LLLT sessions via a laser scanner. Pulsed $808 \mathrm{~nm}$ and $905 \mathrm{~nm}$ laser beams were delivered over the posterior chest for $28 \mathrm{~min}$. The patient was evaluated before and after LLLT by radiological assessment of lung edema (RALE) on chest X-ray, oxygen requirements and saturation, pneumonia severity indices (SMART-COP and BresciaCOVID), blood inflammatory markers (interleukin-6, ferritin, and C-Reactive protein (CRP)). Prior to treatment, oxygen saturation $\left(\mathrm{SpO}_{2}\right.$ ) via pulse oximetry was $88 \%-93 \%$ on 5-6 L oxygen. Following LLLT, $\mathrm{SpO}_{2}$ increased to $97 \%-99 \%$ on $1-3$ L oxygen. Reductions in RALE score from 8 to 3 , BresciaCOVID from 4 to 0 , and SMART-COP from 5 to 0 were observed. Interleukin-6 decreased from 45.89 to $11.7 \mathrm{pg} / \mathrm{mL}$, ferritin from 359 to $175 \mathrm{ng} / \mathrm{mL}$, and CRP from 3.04 to $1.43 \mathrm{mg} / \mathrm{dL}$. Post-treatment, the patient noted appreciable improvement in respiratory symptoms.

Conclusion: Following LLLT our patient showed improvement over a few days in respiratory indices, radiological findings, inflammatory markers, and patient outcomes. This report suggests that adjunct LLLT can be safely combined with conventional treatment in patients with severe COVID-19 and morbid obesity.
\end{abstract}

Key Words: COVID-19; low level laser therapy, LLLT; anti-inflammatory; photobiomodulation; morbid obesity.

\section{INTRODUCTION}

COVID-19 patients with underlying conditions are at higher risk of morbidity and mortality, secondary to the cytokine storm and Acute Respiratory Distress Syndrome (ARDS). The World Health Organization advises that patients with obesity experience more severe symptoms and complications [1], and severe cases of COVID-19 typically require 3-6 weeks for recovery [2].

Obesity leads to mechanical compression of the diaphragm, lungs, and chest cavity, creating restrictive pulmonary damage. Excess fatty tissue decreases respiratory system compliance, while pulmonary resistance is increased, and respiratory muscle strength is decreased [3]. Excess adiposity is associated with elevated inflammatory cytokines and an activated immune system [4]. Severe cases of COVID-19 are characterized by respiratory rates $>30$, oxygen saturation $\leq 93 \%$, and $>50 \%$ involvement of lungs by chest X-ray (CXR). Significantly higher levels of plasma proinflammatory factors such as interleukin-6 (IL-6), ferritin, and C-reactive protein (CRP) predict possible intensive care unit (ICU) admission [5-7]. Serum ferritin levels were found to be most closely related to the severity of COVID-19 [6].

Low level laser therapy (LLLT), also known as photobiomodulation therapy (PBMT) is a noninvasive, safe modality with significant anti-inflammatory effects confirmed by meta-analyses [8]. It is approved for pain management, tissue healing, and lymphedema reduction. In LLLT, transcutaneous application of low-intensity monochromatic light of 400-1000 nm produces intracellular photochemical reactions that activate biomolecules to restore normal cell function and enhance the tissue's healing processes [9].

Adjunct LLLT in human respiratory conditions, including pneumonia, asthma, and chronic obstructive pulmonary disease (COPD), has been shown to reduce respiratory symptoms, normalize respiratory function, shorten recovery times, and improve blood, immunological, and radiological parameters [10-13].

Experimental studies suggest that LLLT modulates the cytokine storm and ARDS via its anti-inflammatory action. Murine models of acute airway and lung inflammation show that LLLT reduces pulmonary microvascular leakage, IL-1 $\beta$, IL-6, and intracellular reactive oxygen species [14-17]. LLLT reduces inflammation at multiple levels and may be an effective strategy to control cytokine storm [14-17]. The use of adjunctive LLLT or PBMT has been recommended as a potential treatment modality to reduce cytokine storm, ARDS, and the need for ventilators in COVID-19 [18, 19].

Here we report the effect of LLLT on CXR, pulmonary severity indices, and select inflammatory markers in a patient with severe COVID-19 and morbid obesity.

\footnotetext{
${ }^{1}$ Ortholazer, Orthopedic Laser Center, 227 Chelmsfort St, Chelmsford, MA, US, 01824

${ }^{2}$ Canadian Optic $\mathcal{E}$ Laser Training Institute, Victoria, BC

${ }^{3}$ Department of Biological Sciences, University of Lethbridge, Lethbridge, $A B$

Correspondence: Soheila Mokmeli, MD, Anesthesiologist, Medical Laser Specialist, Canadian Optic Ë Laser Training Institute, 135-1555 McKenzie Ave. Victoria, BC, V8N1A4, Canada. Tel: 1 (250) 480-7868, E-mail:dr.mokmeli@yahoo.com; soheila@col-center.ca
}

Published online at https://www.cjrt.ca on 28 September 2020 


\section{CASE DESCRIPTION}

A morbidly obese 32-year-old Asian female with a body mass index of 52 and a history of meningioma excision and asthma, presented to the emergency room (ER) with a positive COVID-19 test and shortness of breath, cough, and diarrhea. She was hypoxic with oxygen saturation via pulse oximetry $\left(\mathrm{SpO}_{2}\right)$ of $88 \%$ on room air, tachypneic with respiratory rate of 35 , febrile with temperature of $100.5 \mathrm{~F}$, pulse rate 89 , and blood pressure 106/84. CXR demonstrated bilateral basal multifocal infiltrates. She was admitted on $5 \mathrm{~L} / \mathrm{min}$ of $\mathrm{O}_{2}$. The patient experienced symptoms 7 days prior to presenting to the ER. Upon admission, the patient was confirmed to be SARS-CoV-2 positive by nasopharyngeal swab and reverse transcription-polymerase chain reaction with an Abbott ID system. The patient was started on Ceftriaxone and Azithromycin for potential superimposed bacterial infection. She was considered high risk due to morbid obesity, asthma, low oxygen saturation, infiltrates on CXR, and tachypnea. Her condition worsened despite antibiotics and supportive therapy and was evaluated for ICU admission on hospital day 3. Consent was obtained for the institutional review board (IRB)-approved randomized clinical trial of LLLT for COVID-19. LLLT treatment started on hospital day 3 while antibiotics continued. The patient was not receiving any antiviral or steroid medications.

\section{Pretreatment clinical findings}

The patient's response to LLLT was evaluated via SMART-COP [20] (systolic blood pressure, multilobar infiltrates, albumin, respiratory rate, tachycardia, confusion, oxygen, and $\mathrm{pH}$ ) and Brescia-COVID [21] prediction tools, CXR radiographic assessment of lung edema (RALE) [14], and blood markers of inflammation (Table 2).

The SMART-COP Score [20] evaluates pneumonia severity and predicts the need for intensive respiratory or vasopressor support (IRVS) in community-acquired pneumonia. The pretreatment SMART-COP score was 5 , indicating potential serious progressive complications, rapid referral to the ICU, and the need for a ventilator. The BresciaCOVID Respiratory Severity Scale [21] is a stepwise algorithm for managing patients with confirmed COVID-19. Pretreatment score was 4, which predicted ICU and ventilator support.

The RALE score $[22,23]$ evaluates lung edema by CXR in ARDS patients. To quantify the extent of infection, a severity score was calculated by adapting and simplifying RALE score [15]. A score of 0-4 was assigned to each lung depending on the extent of involvement by consolidation or ground glass opacities $(0=$ no involvement; $1=<25 \%$; $2=25 \%-50 \% ; 3=50 \%-75 \% ; 4=>75 \%$ involvement). The scores for each lung were summed up to produce the final severity score [23]. Before treatment, the RALE score was 8, consistent with $100 \%$ involvement of the lungs.

Prior to LLLT, the patient had significant tachypnea and complained of "terrible shortness of breath" with activities of daily living.

\section{Intervention}

The multiwave locked system (MLS) scanner-equipped laser utilized in this study was deemed a nonsignificant risk device by the US Food and Drug Administration (FDA) prior to obtaining IRB approval. An FDA-cleared laser system (MLS-ASA/Italy) typically used in pain clinics was employed. Two simultaneous and synchronized laser diodes, emitting at 905 and $808 \mathrm{~nm}$, were used in pulsed modes (Table 1). The scanner was positioned $20 \mathrm{~cm}$ above the skin, according to the manufacturer specifications. Each lung was scanned for $14 \mathrm{~min}$, from apex to base over $250 \mathrm{~cm}^{2}$ of the posterior thorax, (Figure 1). The patient tolerated all four consecutive once-daily LLLT without complication.

\section{Post treatment outcomes}

During the first laser treatment, her $\mathrm{SpO}_{2}$ increased from $92 \%$ to $97 \%$ on $3 \mathrm{~L} / \mathrm{min}$ oxygen within $10 \mathrm{~min}$ of starting treatment. After the second laser treatment the patient was breathing without dyspnea. Following treatments her respiratory rate returned to normal 19-20 breaths/min. After the fourth treatment, the patient was able to independently ambulate and had improved ability to perform activities of daily living. Patient was discharged 2 days after her last treatment on $1 \mathrm{~L} / \min$ oxygen. Total hospital stay was 7 days. On follow-up 2 days after discharge, she was weaned to room air. The SMART-COP score decreased from 4 to 1 after treatment, indicating low risk for IRVS and requiring observation only. The Brescia-COVID score decreased from 4 to 0 after treatment, which supports patient monitoring via pulse oximetry and clinical evaluation.

Before treatment, the RALE score was 8, consistent with 100\% involvement of the lungs, and it diminished to three after LLLT. The imaging absorption stage for severe COVID-19 is typically seen after $\geq 14$

\section{TABLE 1}

\section{Laser multiwave locked system parameters for COVID-19 pneumonia}

\begin{tabular}{|c|c|c|}
\hline & $808 \mathrm{~nm}$ (GaAIAs) diode & $905 \mathrm{~nm}$ (GaAs) diode \\
\hline Frequency & $1500 \mathrm{HZ}$, (Duty Cycle $50 \%)(1 \mathrm{~Hz} \div 2 \mathrm{kHz})$ & $1500 \mathrm{HZ}(90 \mathrm{kHz}$ Modulated at $1 \mathrm{~Hz} \div 2 \mathrm{kHz})$ \\
\hline Pulse duration & $500 \mathrm{~ms} \div 250 \mu \mathrm{s}(333 \mu \mathrm{s})$ & $100 \mathrm{~ns}$ \\
\hline Peak power & $3 \mathrm{~W}$ & $75 \mathrm{~W} \times 3$ \\
\hline Average power & $1.5 \mathrm{~W}$ & $11.25 \times 3=33.75 \mathrm{~mW}$ \\
\hline Area & $25 \times 10=250 \mathrm{~cm}^{2}$ & $25 \times 10=250 \mathrm{~cm}^{2}$ \\
\hline Dose & $7.2 \mathrm{~J} / \mathrm{cm}^{2}$ & $113.4 \mathrm{~mJ} / \mathrm{cm}^{2}$ \\
\hline Distance from the skin & \multicolumn{2}{|c|}{$20 \mathrm{~cm}$} \\
\hline Treatment time & \multicolumn{2}{|c|}{14 min each lung } \\
\hline
\end{tabular}




\section{FIGURE 1}

Positioning of the laser beams on the posterior thorax.

The apex of the lung lies above the first rib. The posterior border of the lung extends from the C7 to the T10 vertebra. The laser device (MLS) utilizes a scanner which was positioned $20 \mathrm{~cm}$ above the skin and scanned $250 \mathrm{~cm}^{2}$ over each lung.

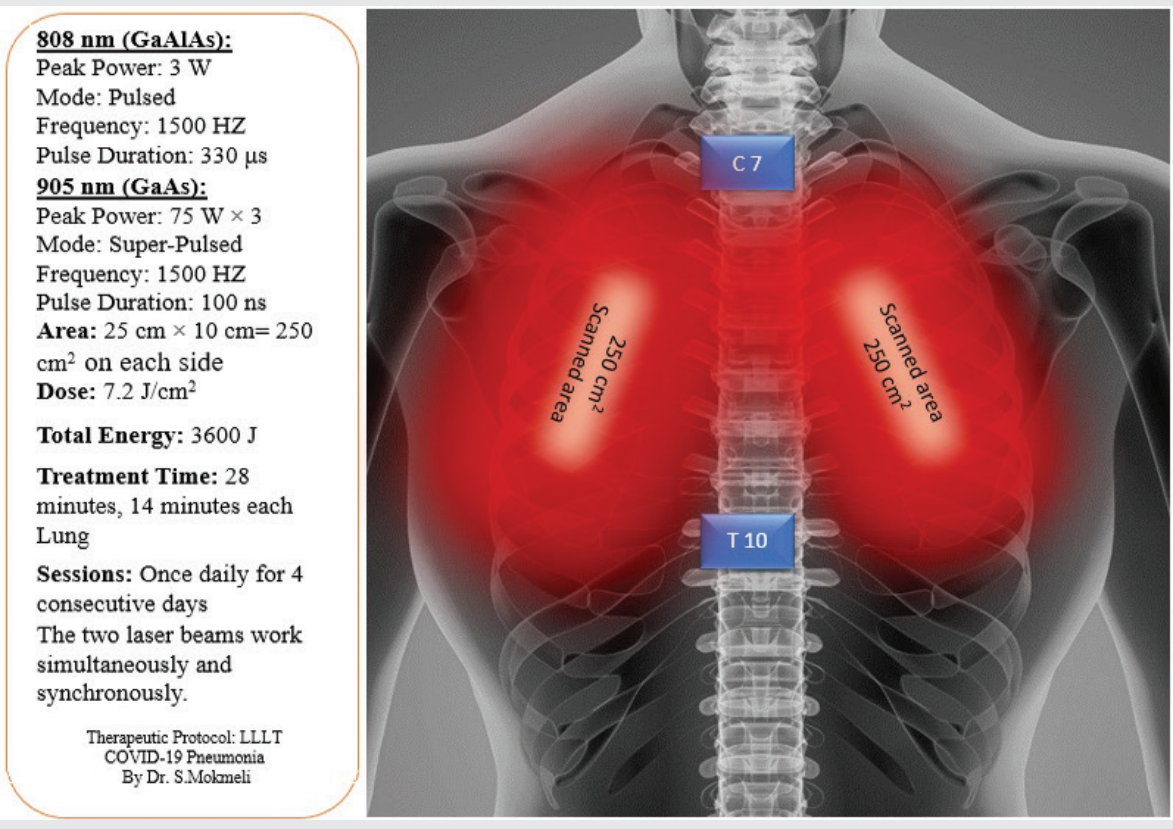

\section{FIGURE 2}

\section{Radiographic assessment of lung edema (RALE) by chest X-ray before and after low level laser therapy.}

The Radiographic Assessment of Lung Edema (RALE) Scores by Chest-X-Ray confirmed the improvement of the lung involvement after Low Level Leaser Therapy for the patient. A score of 0-4 was assigned to each ling, depending on the extent of lung involvement by consolidation or ground glass opacities. $0=$ no lung involvement; $1=<25 \% ; 2=25-50 \% ; 3=50 \%-75 \% ; 4=>75 \%$ involvement. The scores for each lung were summed up to calculate the final severity score. The RALE Scores for the patient were 8 , before laser therapy, and 3, after laser therapy (6 days later).

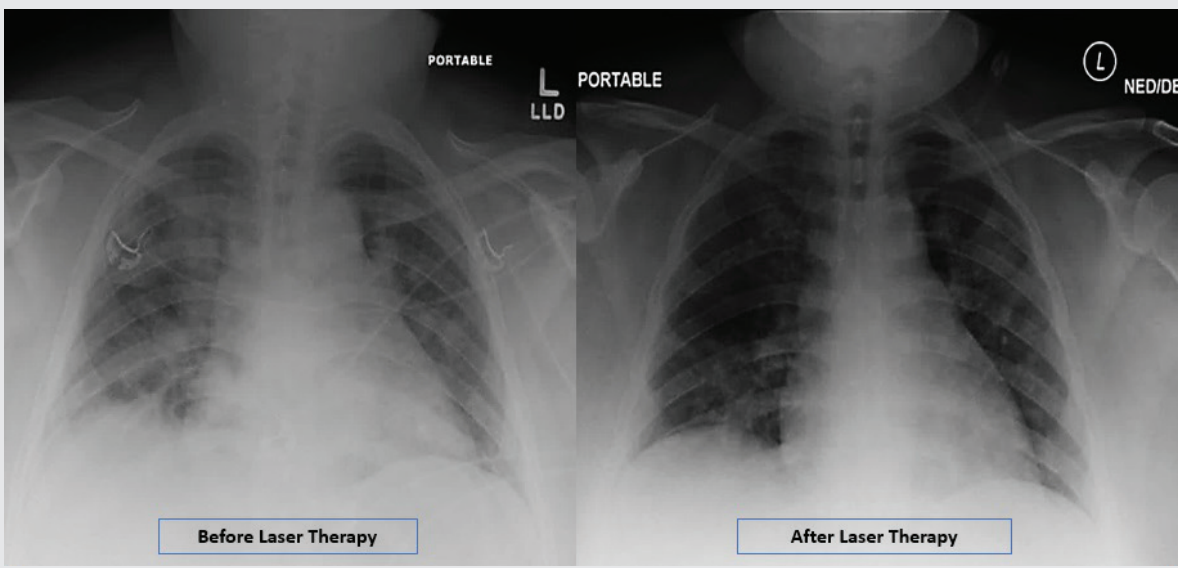

days [24], but in this case, the absorption stage is evident at 7 days (Figure 2).

Blood work included pre- and post-LLLT, IL-6, ferritin, and CRP. Immediately after final treatment IL-6 dropped from 45.89 to $11.7 \mathrm{pg} /$ $\mathrm{mL}$, ferritin from 359 to $175 \mathrm{ng} / \mathrm{mL}$, and CRP improved from 3.06 to $1.43 \mathrm{mg} / \mathrm{dL}$ (Table 2).
Oxygen requirement before treatment was 3-6 L/min with $\mathrm{SpO}_{2}$ 88\%-93\% and improved to $1-3 \mathrm{~L} / \mathrm{min}$ and $\mathrm{SpO}_{2}$ 97\%-99\% after treatment.

At 2 weeks and 6 weeks from discharge the patient reported subjective improvement in respiratory symptoms and well-being. She was satisfied and appreciative of her LLLT experience and treatment outcome. 
TABLE 2

Patient assessments/scores pre- and post-treatment (low level laser therapy) during hospitalization

\begin{tabular}{|c|c|c|c|}
\hline Parameters & Pre-treatment & Post-treatment & Normal range or evaluation criteria \\
\hline $\begin{array}{l}\text { SMART-COP, evaluates } \\
\text { pneumonia severity }\end{array}$ & 5 & 1 & $\begin{array}{l}0 \text { points: Very low risk of needing IRVS } \\
1 \text { point: Low risk ( } 1 \text { in } 20 \text { ) of needing IRVS } \\
2 \text { points: Moderate risk ( } 1 \text { in } 10 \text { ) of needing IRVS } \\
3 \text { points: High risk ( } 1 \text { in } 6 \text { ) of needing IRVS } \\
\geq 4 \text { points: High risk ( } 1 \text { in } 3 \text { ) of needing IRVS; } \\
\text { consider admission to intensive care unit }\end{array}$ \\
\hline $\begin{array}{l}\text { Brescia-COVID } \\
\text { respiratory severity scale }\end{array}$ & 4 & 0 & $\begin{array}{l}0 \text { - monitor } \\
1 \text { - add } \mathrm{O}_{2} \text { and monitor } \\
2 \text { - chest X-ray, arterial blood gas, } \mathrm{O}_{2} \text { therapy, monitor } \\
>2 \text { - High-flow nasal cannula and reassess. If still }>2 \text {, intubate. }\end{array}$ \\
\hline $\begin{array}{l}\text { Radiographic assessment } \\
\text { of lung edema }\end{array}$ & 8 & 2 & $\begin{array}{l}\text { Lungs score dependent on extent of involvement based on } \\
\text { consolidation or ground glass opacities for each lung, total score is } \\
\text { the sum of the score of the lungs: } 0=\text { no involvement. } 1=<25 \% ; 2 \\
=25 \%-50 \% ; 3=50 \%-75 \% ; 4=>75 \%\end{array}$ \\
\hline Interleukin-6 & 45.89 & 11.7 & $<5 \mathrm{pg} / \mathrm{mL}$ \\
\hline C-reactive protein & 3.06 & 1.43 & $0-0.8 \mathrm{mg} / \mathrm{dL}$ \\
\hline $\mathrm{O}_{2}$ requirement & $3-6 \mathrm{~L} / \mathrm{min}$ & $0-1 \mathrm{~L} / \mathrm{min}$ & $0 \mathrm{~L} / \mathrm{min}$ \\
\hline Oxygen saturation & $88 \%-93 \%$ & $97 \%$ & $\geq 94 \%$ \\
\hline Ferritin & 359 & 175 & $11-307 \mathrm{ng} / \mathrm{mL}$, in females \\
\hline White blood cells & 4.4 & 4.9 & $4.5-11 \mathrm{~K} / \mathrm{uL}$ \\
\hline Hemoglobin & 10.6 & 9.0 & $12.0-15.5 \mathrm{~g} / \mathrm{dL}$ \\
\hline Hematocrit & 36 & 30 & $37 \%-48 \%$ for women \\
\hline Albumin & 3.7 & 3.3 & $3.4-5.4 \mathrm{~g} / \mathrm{dL}$ \\
\hline
\end{tabular}

SMART-COP, systolic blood pressure, multilobar infiltrates, albumin, respiratory rate, tachycardia, confusion, oxygen, and pH; IRVS, intensive respiratory or vasopressor support.

\section{DISCUSSION}

Animal and human experimental studies demonstrate that LLLT reduces inflammation at the molecular, cellular, and tissue levels. LLLT is effective against both cytokine storm and ARDS while promoting healing and tissue regeneration. Experimental and animal models of pulmonary disease and infection have revealed multiple cellular and molecular effects, which are both local and systemic. LLLT reduces inflammation without impairing lung function in acute lung injuries and is a promising therapeutic approach for lung inflammatory diseases such as COPD [13-17]. The results of our patient evaluation are consistent with the anti-inflammatory effect of LLLT on the lung, cytokine storm, and ARDS.

The strength of this report is that we measured multiple objective and subjective parameters before and after treatment. We believe that the anti-inflammatory effect of LLLT on lung tissue [13-17] may have occurred in this patient as evidenced by the reduction of pro-inflammatory markers IL- 6 and ferritin. Another strength of the therapy is that the scanning method of this laser has no risk of contamination because the laser does not contact the patient.

To our knowledge, this was the first time that LLLT was used for the treatment of pulmonary disease in COVID-19 patients. The reduction of inflammatory markers and improved radiography support the clinical improvement of the patient. The lasers currently available in pain and lymphedema clinics may be adjusted to treat the lung inflammation in COVID-19. The laser used in our pain clinic was easily adapted to the management of COVID-19 pulmonary disease in a community hospital.

The patient in this case report is part of an ongoing randomized controlled trial. The urgent need for effective COVID-19 treatments calls for pilot studies and clinical trials to further evaluate the potential healing effects of LLLT.

\section{CONCLUSION}

The use of LLLT in the early stage of severe COVID-19 for this patient may have been beneficial and potentially negated the need for ventilator support that was predicted by both Brescia-COVID and SMART-COP scores. Adjunct LLLT in COVID-19 patients may accelerate recovery and reduce the need for ventilator support and ICU admission. This in turn could significantly reduce length of stay, severity of disease, and the clinical burden in our hospitals.

\section{Contributors}

1) Scott Sigman, as research director, contributed to planning, coordinating, and administering the research including, obtaining FDA guided IRB approval, patient recruitment and consent, patient screening and assessments, performing the laser therapy, adverse event monitoring, follow-up, collecting the data, discussion, revising, etc.

2) Soheila Mokmeli, as scientific supervisor, contributed to study methodologies including, designing the therapeutic protocol, determining the assessment tools, materials, instructions on how to conduct the study, verifying case report forms and monitoring overall progress throughout the study, providing the references and discussion, revising, etc.

3) Mariana Vetrici, as scientific advisor, contributed to analyzing data, providing the references, discussion, drafting, and revising the article.

\section{Funding}

There is no funding source and no potential conflict of interest for all authors.

\section{Competing interests}

All authors have completed the ICMJE uniform disclosure form at www. icmje.org/coi_disclosure.pdf and declare: no financial relationships with any organizations that might have an interest in the submitted work in the previous 3 years; no other relationships or activities that could appear to have influenced the submitted work. 


\section{Ethical approval}

The study was performed under FDA guided IRB approval By Clinical Research Review Committee; Lowell General Hospital, Massachusetts, USA.

\section{REFERENCES}

1. Ryan DH, Ravussin E, Heymsfield S. COVID 19 and the patient with obesity - the editors speak out. Obesity (Silver Spring) 2020;28(5):847.

2. World Health Organization. Report of the WHO-China Joint Mission on Coronavirus Disease 2019 (COVID-19). 2020. Available at: https:// www.who.int/docs/default-source/coronaviruse/who-china-joint-mission-on-covid-19-final-report.pdf (Accessed 1 May 2020).

3. Mafort TT, Rufino R, Costa CH, Lopes AJ. Obesity: systemic and pulmonary complications, biochemical abnormalities, and impairment of lung function. Multidiscip Respir Med 2016;11:28.

4. Dixon AE, Peters U. The effect of obesity on lung function. Expert Rev Respir Med 2018;12(9):755-67.

5. Aziz M, Fatima R, Assaly R. Elevated interleukin-6 and severe COVID19: a meta-analysis . J Med Virol. 2020. doi: 10.1002/jmv.25948.

6. Henry BM, de Oliveira MHS, Benoit S, Plebani M, Lippi G. Hematologic, biochemical and immune biomarker abnormalities associated with severe illness and mortality in coronavirus disease 2019 (COVID-19): a meta-analysis. Clin Chem Lab Med 2020;58(7):1021-8.

7. Vargas-Vargas M, Cortés-Rojo C. Ferritin levels and COVID-19. Rev Panam Salud Publica 2020;44:e72.

8. Bjordal JM, Lopes-Martins RAB, Joensen J, Iversen VV. The anti-inflammatory mechanism of low level laser therapy and its relevance for clinical use in physiotherapy. Phys Ther Rev 2010;15(4):286-93.

9. Hamblin MR. Mechanisms and applications of the anti-inflammatory effects of photobiomodulation. AIMS Biophys 2017;4(3):337-61.

10. Amirov NB. Pokazateli membrannol pronitsaemosti, mikrotsirkuliatsii, funktsii vneshnegio dykhaniia i soderzhanie mikroélementov pri medikamentozno-lazernol̆ terapii pnevmonii [Parameters of membrane permeability, microcirculation, external respiration, and trace element levels in the drug-laser treatment of pneumonia]. Ter Arkh 2002; 74(3):40-3.

11. Derbenev VA, Mikhailov VA, Denisov IN. Use of low-level laser therapy (LLLT) in the treatment of some pulmonary diseases: ten-year experience. Proc SPIE 1999;4166:323-5.

12. Ostronosova NS. Outpatient use of laser therapy in bronchial asthma. Ter Arkh 2006;78(3):41-4.
13. Mehani SHM. Immunomodulatory effects of two different physical therapy modalities in patients with chronic obstructive pulmonary disease. J Phys Ther Sci 2017;29(9):1527-33.

14. Aimbire F, Albertine R, de Magalhães RG, et al. Effect of LLLT Ga-Al-As $(685 \mathrm{~nm})$ on LPS-induced inflammation of the airway and lung in the rat. Lasers Med Sci 2005;20(1):11-20.

15. Aimbire F, Lopes-Martins RA, Albertini R, et al. Effect of low-level laser therapy on hemorrhagic lesions induced by immune complexes in rat lungs. Photomed Laser Surg 2007;25(2):112-17.

16. Aimbire F, Ligeiro de Oliveira AP, Albertini R, et al. Low level laser therapy (LLLT) decreases pulmonary microvascular leakage, neutrophil influx and IL-1beta levels in airway and lung from rat subjected to LPS. induced inflammation. Inflammation 2008;31(3):189-97.

17. Oliveira MC Jr, Greiffo FR, Rigonato-Oliveira NC, et al. Low level laser therapy reduces acute lung inflammation in a model of pulmonary and extrapulmonary LPS-induced ARDS. J Photochem Photobiol B 2014;134:57-63. doi: 10.1016/j.jphotobiol.2014.03.021.

18. Mokmeli S, Vetrici M. Low level laser therapy as a modality to attenuate cytokine storm at multiple levels, enhance recovery, and reduce the use of ventilators in COVID-19. Can J Respir Ther 2020;56:1-7.

19. Enwemeka CS, Bumah VV, Masson-Meyers DS. Light as a potential treatment for pandemic coronavirus infections: a perspective. J Photochem Photobiol B 2020;207:111891.

20. Charles PG, Wolfe R, Whitby M, et al. SMART-COP: a tool for predicting the need for intensive respiratory or vasopressor support in community-acquired pneumonia. Clin Infect Dis 2008;47(3):375-84. Available at: https://www.mdcalc.com/smart-cop-score-pneumonia-severity (Accessed 28 July 2020).

21. Duca A, Piva S, Focà E, Latronico N, Rizzi M. Calculated decisions: Brescia-COVID Respiratory Severity Scale (BCRSS)/algorithm. Emerg Med Pract 2020;22(5 Suppl):CD1-CD2. Available at: https://www. mdcalc.com/brescia-covid-respiratory-severity-scale-bcrss-algorithm\# why-use (Accessed 28 July 2020).

22. Zimatore C, Pisani L, Lippolis V, et al. The radiographic assessment of lung edema (RALE) score has excellent diagnostic accuracy for ARDS. Eur Respir J 2019;54(Suppl. 63):OA3299.

23. Wong HYF, Lam HYS, Fong AH, et al. Frequency and distribution of chest radiographic findings in patients positive for COVID-19. Radiology 2020;296(2):E72-E78.

24. Pan F, Ye T, Sun P, et al. Time course of lung changes at chest CT during recovery from coronavirus disease 2019 (COVID-19). Radiology 2020;295(3):715-21. 